CrossMark \& click for updates

Cite this: Org. Biomol. Chem., 2014, 12, 6208

\title{
The Escherichia coli glucuronylsynthase promoted synthesis of steroid glucuronides: improved practicality and broader scope $\uparrow$
}

\begin{abstract}
Paul Ma, Nicholas Kanizaj, Shu-Ann Chan, David L. Ollis and Malcolm D. McLeod*
A library of steroid glucuronides was prepared using the glucuronylsynthase derived from Escherichia coli $\beta$-glucuronidase, followed by purification using solid-phase extraction. A representative range of steroid substrates were screened for synthesis on the milligram scale under optimised conditions with conversions dependent on steroid substitution and stereochemistry. Epiandrosterone ( $3 \beta$-hydroxy- $5 \alpha$-androstan-17-one) provided the highest conversion of $90 \%$ ( $84 \%$ isolated yield). The previously unreported

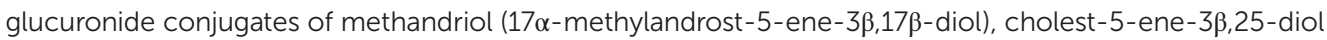
and the designer steroid trenazone (17 $\beta$-hydroxyestra-4,9-dien-3-one) were prepared on a multi-milligram scale suitable for characterisation by ${ }^{1} \mathrm{H}$ and ${ }^{13} \mathrm{C}$ NMR spectroscopy. The glucuronide conjugate of $d_{5}$-etiocholanolone $\left(2,2,3,4,4-d_{5}-3 \alpha\right.$-hydroxy-5 $\beta$-androstan-17-one), a target developed by the World Anti-Doping Agency as a certified reference material, was also prepared on a milligram scale. The improved E. coli glucuronylsynthase method provides for the rapid synthesis and purification of steroid glucuronides on a scale suitable for a range of analytical applications.
\end{abstract}

Received 13th May 2014

Accepted 1st July 2014

DOI: $10.1039 / c 40 b 00984 c$

www.rsc.org/obc

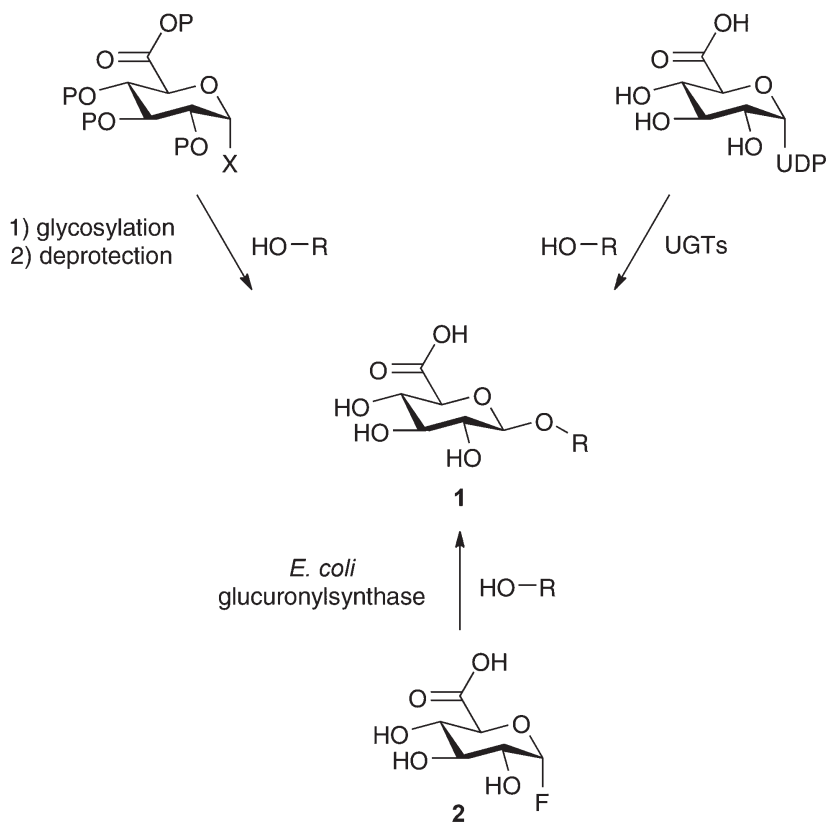

Scheme 1 Preparation of glucuronide conjugates.

desired glucuronide. ${ }^{1,11}$ In addition, the need for watersensitive activators and glycosyl donors, and the requirement for protecting groups makes small-scale synthesis for analytical purposes challenging. 
The enzymatic approach consists of two major methods, the first of which utilises the mammalian uridine 5 '-diphosphoglucuronosyltransferase (UGT) enzyme family to perform the glucuronylation in a single step. ${ }^{12-15}$ This method has the advantage of avoiding protecting groups, but employs a sensitive and expensive uridine 5'-diphosphoglucuronic acid donor and requires expression of the membrane-bound UGT enzymes. ${ }^{16}$ Difficulties in the expression and purification of UGTs mean that animal sacrifice is often used to obtain sufficient quantities of enzyme for synthesis, which gives rise to additional ethical considerations. ${ }^{12-14}$

The second enzymatic method developed by the McLeod group employs the glucuronylsynthase derived from E. coli $\beta$-glucuronidase. ${ }^{17,18}$ The glucuronylsynthase is derived by single-point mutation of the wild-type enzyme, which disables glycosyl hydrolase activity but allows for glycoside synthesis when used in combination with a synthetically-derived $\alpha$-D-glucuronyl fluoride 2 donor. ${ }^{19,20}$ This method also performs glucuronylation in a single step but has some added advantages over the UGT-based approach in that the E. coli glucuronylsynthase is a soluble bacterial enzyme that is readily expressed and purified and the $\alpha$-D-glucuronyl fluoride 2 substrate is readily accessible in four synthetic steps from D-glucose.

Steroid glucuronides are an important class of compounds in the field of sports drug testing, with many endogenous and exogenous steroids excreted primarily as glucuronide conjugates. ${ }^{21}$ As a result, significant work has been undertaken on both the synthesis and analysis of steroid glucuronides. ${ }^{13,14,22,23}$ In previous work we outlined a three-step approach based on the temporary introduction of solubilising substituents for the glucuronylsynthase-mediated synthesis of steroid glucuronides. ${ }^{17}$ Although effective, the addition and deletion of solubilising substituents proved somewhat unwieldy and lacking in generality. In this paper we report on the development of an improved method for the single-step glucuronylsynthase-mediated synthesis and purification of steroid glucuronides on a scale suitable for a range of analytical applications.

\section{Results and discussion}

The glucuronylation protocol developed has three main components: the glucuronylsynthase enzyme, the syntheticallyderived $\alpha$-D-glucuronyl fluoride 2 donor and a suitable acceptor alcohol (Scheme 2). ${ }^{17}$ In this paper the substrates were steroidal alcohols of different constitutions and stereochemistries. The reactions were carried out in a mixed $10 \% \mathrm{v} / \mathrm{v}$ tertbutanol-sodium phosphate buffer at $\mathrm{pH} 7.5$ and $37^{\circ} \mathrm{C}$ for $2 \mathrm{~d}$. We observed that conducting the reactions in the presence of tert-butanol led to a significant increase in steroid solubility without the co-solvent serving as a substrate or having a deleterious effect on enzyme activity, obviating the need for solubilising substituents to obtain reasonable solubility and hence useful enzyme-catalysed reaction rates. ${ }^{17}$ This contrasts with
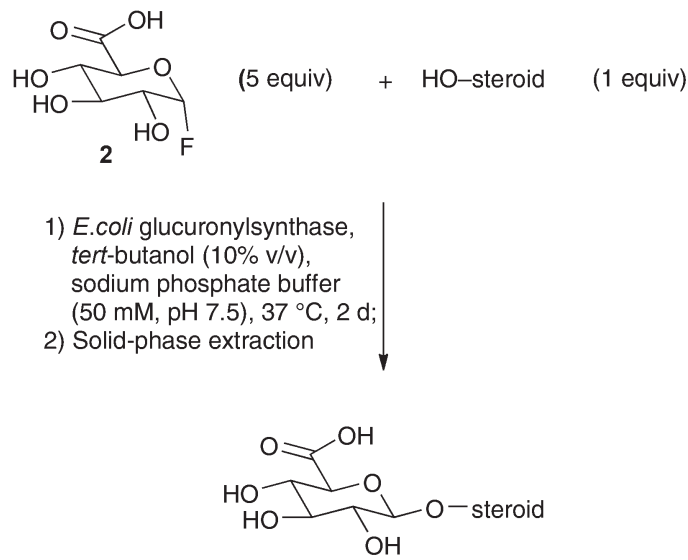

Scheme 2 The glucuronylsynthase protocol.

the influence of tert-butanol co-solvent ( 5 or $10 \% \mathrm{v} / \mathrm{v}$ ) on the glucuronylation of 2-phenylethanol that shows moderately reduced enzyme activity. ${ }^{17}$ The wild-type $\beta$-glucuronidasemediated hydrolysis of para-nitrophenyl $\beta$-D-glucuronide also shows reduced activity in the presence of tert-butanol cosolvent ( 5 or $10 \% \mathrm{v} / \mathrm{v}$ ), albeit with similar long-term enzyme stability relative to buffer alone. ${ }^{17}$

To facilitate the rapid purification of the glucuronide product from residual steroidal alcohol, non-volatile salts and other reaction components, we developed a method based on commercially available solid-phase extraction (SPE) cartridges. Our SPE purification employed Oasis WAX cartridges containing a mixed-mode polymeric/weak anion exchange resin. Cartridges were conditioned with methanol and water and then loaded with the crude reaction mixture. The cartridge was then washed with $2 \%$ aqueous formic acid, water and then methanol to elute any residual steroidal alcohol substrate. The steroidal glucuronide was eluted with saturated aqueous ammonium hydroxide in methanol $(5 \% \mathrm{v} / \mathrm{v})$. The target glucuronides were afforded in high purity after evaporation of the eluant under reduced pressure. The ${ }^{1} \mathrm{H}$ NMR spectra of the SPE purified materials so obtained were fully consistent with the proposed structures and are reproduced in the ESI. $\dagger$ Our investigations revealed that reactions using $1 \mathrm{mg}$ of steroidal alcohol were readily purified using a single $60 \mathrm{mg}$ resin $(3 \mathrm{cc})$ SPE cartridge. Larger scale synthesis required purification in parallel or the use of larger $500 \mathrm{mg}$ resin $(6 \mathrm{cc}$ ) cartridges.

Given the typically small scale of the synthesis, determining the mass of product and hence chemical yield with precision was not feasible. To address this we elected to monitor the conversion of starting material to product by ${ }^{1} \mathrm{H}$ NMR integration. Omitting the methanol wash step in the SPE method outlined above resulted in the elution by methanolic ammonia of a combined fraction containing both free steroid and steroid glucuronide. This was then subjected to 400 or $600 \mathrm{MHz}{ }^{1} \mathrm{H}$ NMR integration of selected steroidal protons in both the starting material and product allowing for the determination of reaction conversion as reported in Table 1. For the secondary steroidal alcohols studied, glucuronylation typically 
Table 1 Synthesis of steroid glucuronides

\begin{tabular}{|c|c|c|c|c|c|}
\hline Entry $^{a}$ & Glucuronide product & $\begin{array}{l}\text { Conv. }^{b}(\%) \\
{\text { (yield } \%)^{c}}^{c}\end{array}$ & Entry $^{a}$ & Glucuronide product & 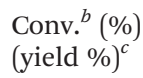 \\
\hline 1 & $\mathrm{HO} \mathrm{OH}_{\mathrm{OH}}$ & $50^{d}$ & 10 & & $36^{d, f}(26)$ \\
\hline
\end{tabular}

2

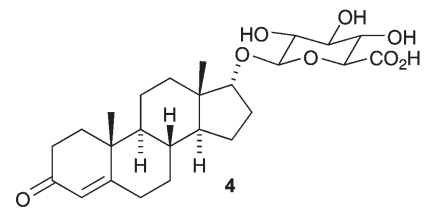

3
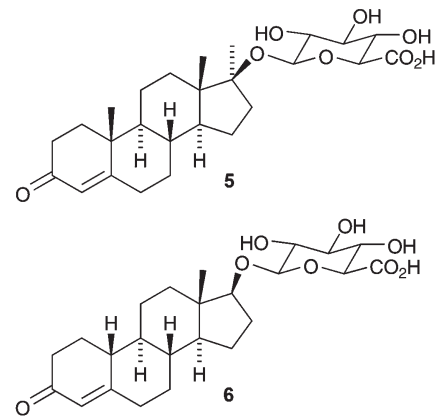

5

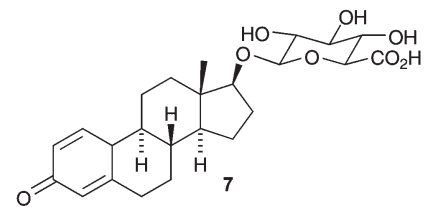

6

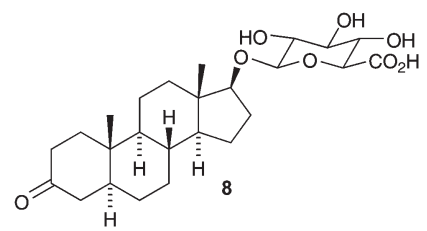

7

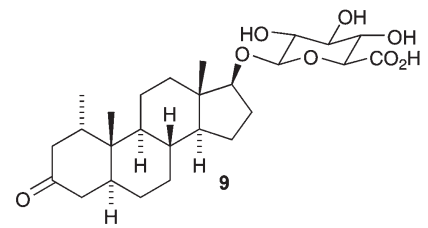

8

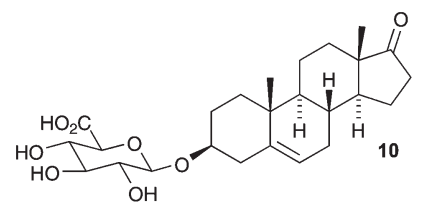

9

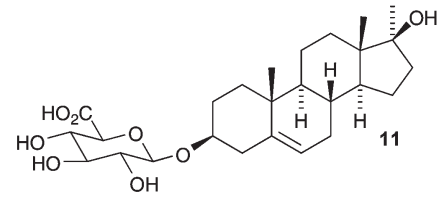

$28^{d}$

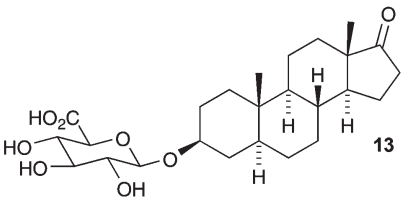

$<5^{e}$

12

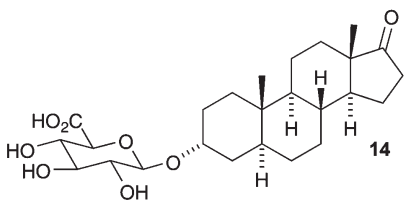

$64^{d}$

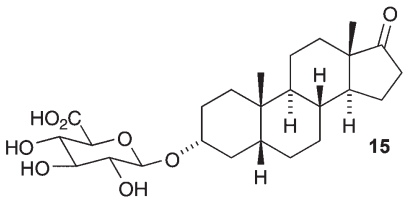

$8^{d}$

14

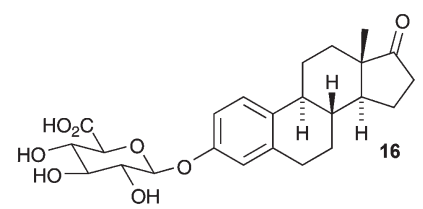

$13^{d}$

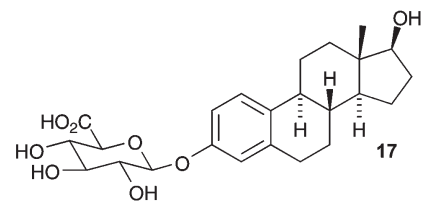

$12^{d}$

16

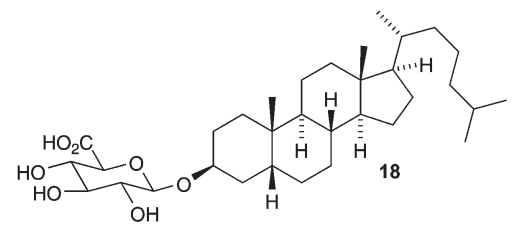

$87^{d, f}(94)$

17

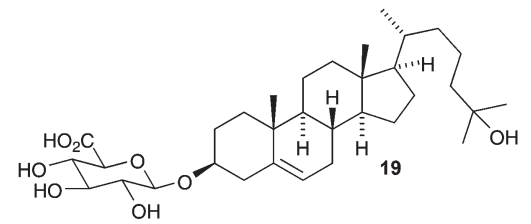

$32^{d, f}(15)$

18 $90^{d, f}(84)$

$<5^{e}$

$25^{d}(20)$

$33^{d}$

$88^{d, g}$

$20^{d, f}(8)$

$21^{d, f}(34)$

\footnotetext{
${ }^{a}$ Reaction conditions: steroid (1.0 equiv.), $\alpha$-D-glucuronyl fluoride (5.0 equiv.), E. coli glucuronylsynthase $\left(0.2 \mathrm{mg} \mathrm{mL}^{-1}\right)$, tert-butanol $(10 \% \mathrm{v} / \mathrm{v})$, sodium phosphate buffer $(50 \mathrm{mM}, \mathrm{pH} 7.5), 37^{\circ} \mathrm{C}, 2 \mathrm{~d} .{ }^{b}$ Determined by 400 or $600 \mathrm{MHz}{ }^{1} \mathrm{H}$ NMR integration. ${ }^{c}$ Isolated yield of pure glucuronide for reactions on $5-10 \mathrm{mg}$ scale. ${ }^{d}$ The 400 or $600 \mathrm{MHz}{ }^{1} \mathrm{H}$ NMR spectrum is provided in the ESI. ${ }^{e}$ Conversion $<5 \%$ as determined by $400 \mathrm{MHz}$ ${ }^{1} \mathrm{H}$ NMR integration. ${ }^{f}$ The $150 \mathrm{MHz}{ }^{13} \mathrm{C}$ NMR spectrum is provided in the ESI. ${ }^{g}$ Eluted as a $1.0: 1.6: 1.1$ mixture of 3-mono-, 17 -mono- and 3,17-bis-glucuronides as determined by $600 \mathrm{MHz}{ }^{1} \mathrm{H}$ NMR integration.
} 
resulted in a $0.24-0.31 \mathrm{ppm}$ downfield shift of the oxymethine proton at the reaction site, with the anomeric proton showing a coupling constant $\left({ }^{3} J_{1,2}=7.7-8.0 \mathrm{~Hz}\right)$ consistent with $\beta$-glycoside formation. For the phenolic substrates estrone and estradiol, glucuronylation resulted in a $0.32-0.34 \mathrm{ppm}$ downfield shift of the protons ortho to the reaction site, with the anomeric proton obscured by water from the deuterated methanol solvent. The conversion showed good reproducibility for the glucuronylation of dehydroepiandrosterone (87, 90 and 94\% conversion, $n=3$ ), testosterone (48 and 50\%), methandriol (32 and $33 \%)$ and estrone (29, 30 and $33 \%)$, such that we now routinely assess enzyme activity by monitoring the small scale reaction conversion of dehydroepiandrosterone. In examples where larger scale synthesis was conducted (entries 8-11, 13, $17,18)$ the isolated yields showed reasonable concordance with the reported conversions.

The glucuronide products 3-20 resulting from a screen of eighteen different steroidal alcohols possessing a range of different constitutions and stereochemistries are shown in Table 1. Several trends were evident in the observed conversions with steroids possessing $3 \beta$ - or $17 \beta$-hydroxy groups giving higher conversions under the glucuronylation conditions than those with $3 \alpha$ - or $17 \alpha$-hydroxy groups ( $c f$. entries 1 and 2,11 and 12). In addition, 3 $\beta$-hydroxyandrostane derivatives (entries 8-11) generally gave higher conversions than their $17 \beta$-hydroxy congeners (entries 1, 4-7 and 18), which may be attributed to the slightly higher steric bulk resulting from the neighbouring C18 methyl group or other unfavourable enzyme-substrate interactions. The two steroids with highest conversion were dehydroepiandrosterone (entry 8) and epiandrosterone (entry 11), while stereochemically distinct substrates such as etiocholanolone (entry 13) and androsterone (entry 12) were less productive. Despite the changes in reactivity, the glucuronylation was effective for a wide range of common 3, 5 and 17 steroidal stereochemistries and substitution patterns. In the majority of cases (Table 1), conducting the reaction on a 1-2 $\mathrm{mg}$ scale afforded sufficient pure glucuronide to conduct 400 or $600 \mathrm{MHz}{ }^{1} \mathrm{H}$ NMR analysis. The broad substrate scope of this enzyme catalysed synthesis is noteworthy but has parallels in the use of wild-type E. coli $\beta$-glucuronidase in analytical applications. During routine screening for the presence of steroidal compounds in athlete samples, $\beta$-glucuronidase is employed to hydrolyse the combined glucuronide fraction to give free steroids prior to derivatisation and analysis by GCMS. ${ }^{24}$ This protocol relies on the promiscuity of the enzyme to catalyse the hydrolysis of the wide range of steroid glucuronides present with few exceptions. $^{25,26}$ The glucuronylsynthase enzyme used in this study appears to retain analogous promiscuity, albeit with an efficacy that depends on steroid substitution patterns.

Methyltestosterone (entry 3) was one of three tertiary alcohols that were examined, with the corresponding glucuronide 5 obtained in only trace amounts ( $<5 \%$ conversion), detectable by mass spectrometry but not ${ }^{1} \mathrm{H}$ NMR. This is likely due to the high steric hindrance afforded by both the C18 and C20 methyl groups that impede access of the
$17 \beta$-hydroxy group to the glycosyl donor. This parallels the low reactivity observed for methyltestosterone in the KoenigsKnorr glycosylation and deprotection sequence, affording a low $3.5 \%$ yield of the methyltestosterone 17 -glucuronide. ${ }^{27}$ Little or no reactivity for methyltestosterone glucuronylation is observed for recombinant human UGTs and human liver microsomes. ${ }^{15}$ Low yields are also reported for glucuronylation using rat liver microsomes. ${ }^{13}$ For methandriol (entry 9), which possesses both a secondary $3 \beta$ - and tertiary $17 \beta$-hydroxy groups, and cholest-5-ene-3 $\beta, 25$-diol (entry 17 ) which possesses both a secondary $3 \beta$ - and tertiary 25 -hydroxy groups, glucuronylation was observed to take place regioselectively at the secondary hydroxy group. In both examples a $0.26 \mathrm{ppm}$ downfield shift of the $\mathrm{H} 3$ proton was observed consistent with glucuronylation at H3. Estradiol which possesses both phenolic 3- and secondary $17 \beta$-hydroxy groups afforded a mixture of 3-mono-, 17-mono- and 3,17-bis-glucuronides in an 1.0:1.6:1.1 ratio as determined by $600 \mathrm{MHz}{ }^{1} \mathrm{H}$ NMR integration.

For some substrates such as androstanolone (entry 6) and the cholesterol derivatives (entries 16, 17), solubility posed a particular problem that likely contributed to the low conversion - for example, only trace amounts of coprostanol 3-glucuronide (entry 16) was observed. The co-solvent tert-butanol was used to enhance steroid solubility in the aqueous reaction media and was able to dissolve the majority of steroid substrates used in this study at a final concentration of $\sim 0.69 \mathrm{mM}$, but for the substrates mentioned above only partial dissolution was achieved and so the reactions were conducted on the resulting saturated solutions.

During this study we found that the literature contained little NMR characterisation data for several known glucuronide products that were prepared in the screen. To redress this, we scaled up our syntheses for these substrates, specifically for pregnenolone and epiandrosterone (entries 10 and 11), obtaining full ${ }^{1} \mathrm{H}$ and ${ }^{13} \mathrm{C}$ NMR data for each. Three of the substrates investigated, methandriol, cholest-5-ene-3 $\beta, 25$-diol and the designer steroid trenazone (entries 9, 17 and 18), ${ }^{28}$ gave rise to previously un-reported glucuronide conjugates 11, 19 and 20 that were also prepared on a scale suitable for characterisation by ${ }^{1} \mathrm{H}$ and ${ }^{13} \mathrm{C}$ NMR spectroscopy.

One of the aims of our work was to provide a simple and effective alternative protocol for the synthesis of steroid glucuronides, in particular for small scale research applications where traditional methods of glucuronide synthesis fail or encounter significant practical difficulties. One such application is the synthesis of glucuronide conjugates from rare and expensive deuterated steroids. The deuterated steroid conjugate $\mathrm{d}_{5}$-etiocholanolone 3-glucuronide 21 is a compound developed by the World Anti-Doping Agency (WADA) as a reference material to facilitate the longitudinal monitoring of testosterone abuse. ${ }^{29}$ In our hands a commercially-derived one milligram sample of $\mathrm{d}_{5}$-etiocholanolone 22 was converted to the corresponding glucuronide 21 conjugate on a sufficient scale to conduct $600 \mathrm{MHz}$ NMR analysis (Scheme 3). The resulting conjugate showed an absence of the $\mathrm{H} 3$ proton signal of the non-deuterated counterpart at $\delta_{\mathrm{H}} 3.81$ together 

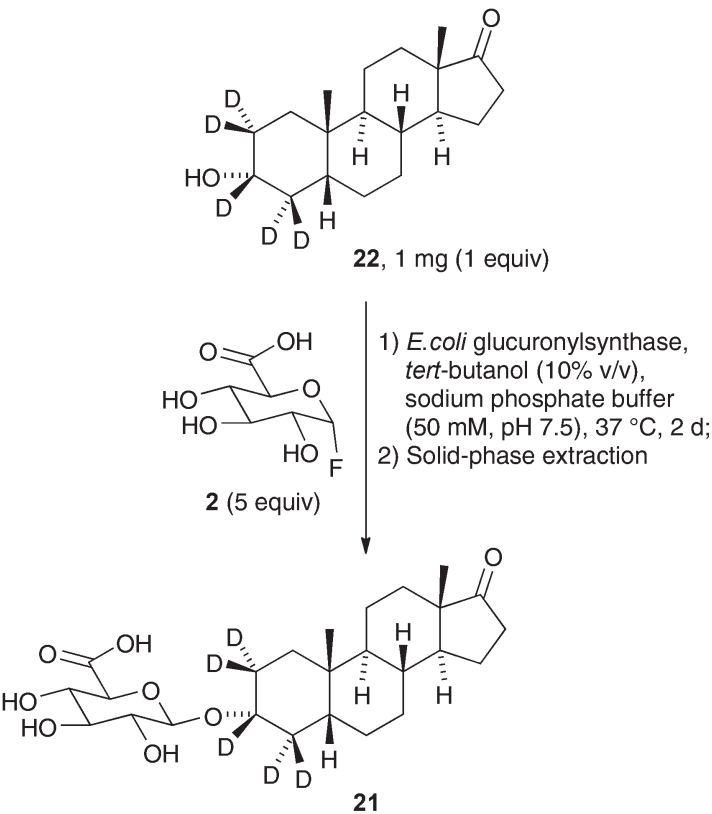

Scheme 3 Synthesis of $d_{5}$-etiocholanolone 3-glucuronide 21 .

with simplification of the aliphatic region from $\delta_{\mathrm{H}}$ 1.98-0.98 consistent with per-deuteration of the A-ring. High-resolution mass spectrometry under negative ESI also revealed an ion $\left([\mathrm{M}-\mathrm{H}]^{-}, m / z\right.$ 470.2800) consistent with the $\mathrm{d}_{5}$-etiocholanolone 3-glucuronide 21.

The glucuronylation of two additional ${ }^{17,18}$ non-steroidal acceptors was investigated that hints at a wider substrate scope for the glucuronylsynthase protocol (Table 2). This resulted in the formation of 4-methylumbeliferone 7-glucuronide $23^{30}$ and chloramphenicol 3-glucuronide $24 .^{31}$ Chloramphenicol glucuronide has previously been prepared by UGT-mediated synthesis. ${ }^{31}$ During comparison with the literature data we noted that the published ${ }^{1} \mathrm{H}$ NMR data and spectra were incorrectly referenced but accounting for this, the data and spectra cor-

Table 2 Synthesis of non-steroidal glucuronides

Entry $^{a}$ Glucuronide product

${ }^{a}$ Reactions conditions: acceptor (1.0 equiv.), $\alpha$-D-glucuronyl fluoride (5.0 equiv.), E. coli glucuronylsynthase $\left(0.2 \mathrm{mg} \mathrm{mL}^{-1}\right)$, tert-butanol $(10 \% \mathrm{v} / \mathrm{v})$, sodium phosphate buffer $(50 \mathrm{mM}, \mathrm{pH} 7.5), 37^{\circ} \mathrm{C}, 2 \mathrm{~d}$. ${ }^{b}$ Determined by 400 or $800 \mathrm{MHz}{ }^{1} \mathrm{H}$ NMR integration. ${ }^{c}$ The 400 or $800 \mathrm{MHz}{ }^{1} \mathrm{H}$ NMR spectrum is provided in the ESI. ${ }^{d}$ The $800 \mathrm{MHz} 2 \mathrm{D}$ HSQC and HMBC spectra are provided in the ESI. responded well with the material produced in this work. The regioselectivity of glucuronylation was supported by the downfield shift ( 0.19 and $0.10 \mathrm{ppm})$ of the $\mathrm{H} 3$ protons and a HMBC three bond correlation between one $\mathrm{H} 3$ proton (4.00 ppm) and the anomeric carbon (104.2 ppm). Finally, although the results of this study have focussed on small scale synthesis compatible with rapid SPE purification, we also note that the glucuronylsynthase method reported here is readily scalable. In previous work the glucuronylsynthase has been used for the larger scale synthesis of a testosterone 17-glucuronide derivative (72\% yield, $54 \mathrm{mg}$ ) and 2-phenylethanol glucuronide (96\% yield, $718 \mathrm{mg}) .{ }^{17,18}$

\section{Conclusion}

A library of steroid glucuronides was prepared using the glucuronylsynthase derived from Escherichia coli $\beta$-glucuronidase, followed by purification using solid-phase extraction. The improved protocol demonstrated broad substrate scope, with fifteen out of eighteen substrates providing glucuronide conjugate in high purity and on a scale suitable for ${ }^{1} \mathrm{H}$ NMR analysis. The method allows for the rapid synthesis and purification of glucuronide conjugates on a small scale and avoids many of the complications associated with traditional chemical or enzymatic approaches. The reliability and efficiency of this method is highlighted by the preparation of a $\mathrm{d}_{5}$-etiocholanolone 3-glucuronide $\mathbf{2 1}$ from a commercially-derived one milligram sample of the deuterated steroid $\mathrm{d}_{5}$-etiocholanolone 22. It is envisaged that the $E$. coli glucuronylsynthase system will help meet the future demand for glucuronide standards in analytical applications. Further engineering, directed to increasing the substrate scope and improving the catalytic efficiency of the glucuronylsynthase enzyme is in progress and will be reported in due course.

\section{Experimental}

\section{Epiandrosterone 3-glucuronide $13^{32}$}

Method A (conversion by ${ }^{\mathbf{1}} \mathbf{H}$ NMR analysis). Epiandrosterone $(1.00 \mathrm{mg}, 3.44 \mu \mathrm{mol})$ was dissolved in tert-butanol $(500 \mu \mathrm{L})$ and sodium phosphate buffer (3.22 mL, $50 \mathrm{mM}, \mathrm{pH} 7.5)$. Glucuronylsynthase $\left(0.92 \mathrm{~mL}, 1.09 \mathrm{mg} \mathrm{mL}{ }^{-1}\right.$, final concentration $0.2 \mathrm{mg} \mathrm{mL}^{-1}$ ) and $\alpha$-D-glucuronyl fluoride 2 (3.89 $\mathrm{mg}$, $18.2 \mu \mathrm{mol}, 5$ equiv.) dissolved in sodium phosphate buffer (365 $\mu \mathrm{L}, 50 \mathrm{mM}$ ) were added and the reaction incubated without agitation at $37^{\circ} \mathrm{C}$ for 2 days. The reaction was then subjected to solid-phase extraction. An Oasis WAX SPE cartridge (60 mg, $3 \mathrm{~mL}$ ) was pre-conditioned with methanol $(1 \mathrm{~mL})$ and milliQ water $(3 \mathrm{~mL})$. The crude reaction was loaded onto the cartridge and washed with aqueous formic acid ( $3 \mathrm{~mL}, 2 \% \mathrm{v} / \mathrm{v})$, milliQ water $(3 \mathrm{~mL})$, and finally with saturated aqueous ammonium hydroxide in methanol $(9 \mathrm{~mL}, 5 \% \mathrm{v} / \mathrm{v})$. The appropriate fractions were combined and the solvent removed under reduced pressure at $30{ }^{\circ} \mathrm{C}$ to afford a mixture 
of epiandrosterone and epiandrosterone 3-glucuronide with a $90 \%$ conversion as determined by $600 \mathrm{MHz}{ }^{1} \mathrm{H}$ NMR integration of the $\mathrm{H} 3$ protons. A copy of the ${ }^{1} \mathrm{H}$ NMR conversion spectrum is reproduced in the ESI. $\dagger$

Method B (synthesis). The reaction was carried out as for method A on a larger scale with epiandrosterone $(5.03 \mathrm{mg}$, $1.73 \mu \mathrm{mol})$. The reaction was then subjected to solid-phase extraction. An Oasis WAX SPE cartridge (500 mg, $6 \mathrm{~mL}$ ) was pre-conditioned with methanol $(5 \mathrm{~mL})$ and milliQ water $(15 \mathrm{~mL})$. The crude reaction was loaded onto the cartridge and washed with aqueous formic acid (15 mL, 2\% v/v), milliQ water $(15 \mathrm{~mL})$, methanol $(15 \mathrm{~mL})$ to elute free steroid, and finally with saturated aqueous ammonium hydroxide in methanol $(30 \mathrm{~mL}, 5 \% \mathrm{v} / \mathrm{v})$ to elute the steroid glucuronide. The appropriate fractions were combined and the solvent removed under reduced pressure at $30{ }^{\circ} \mathrm{C}$ to afford epiandrosterone 3-glucuronide 13 as a white solid (6.8 mg, 84\%). Copies of the ${ }^{1} \mathrm{H}$ and ${ }^{13} \mathrm{C}$ NMR spectra are reproduced in the ESI. $\dagger R_{\mathrm{f}} 0.44$ ( $7: 2: 1$ EtOAc-MeOH- $\left.{ }_{2} \mathrm{O}\right) ; \delta_{\mathrm{H}}\left(600 \mathrm{MHz}, \mathrm{CD}_{3} \mathrm{OD}\right) 4.41(1 \mathrm{H}$, d, $\left.J_{\mathrm{H} 20-\mathrm{H} 21} 8.0, \mathrm{H} 20\right), 3.78$ (1 H, m, H3), 3.55 (1 H, d, $J_{\mathrm{H} 24-\mathrm{H} 23}$ 9.5, H24), 3.43 (1 H, t, $\left.J_{\mathrm{H} 23-\mathrm{H} 24} \approx J_{\mathrm{H} 23-\mathrm{H} 22} 9.2, \mathrm{H} 23\right), 3.39(1 \mathrm{H}$, $\left.\mathrm{t}, J_{\mathrm{H} 22-\mathrm{H} 23} \approx J_{\mathrm{H} 22-\mathrm{H} 21} 8.9, \mathrm{H} 22\right), 3.18\left(1 \mathrm{H}, \mathrm{t}, J_{\mathrm{H} 21-\mathrm{H} 22} \approx J_{\mathrm{H} 21-\mathrm{H} 20}\right.$ 8.4, H21), 2.43 (1 H, dd, J 19.3, 8.7), 2.06 (1 H, dt, $J 19.3,9.4$ ) 1.97-1.91 (2 H, m), 1.83 (1 H, m), 1.75-1.49 (7 H, m), 1.40-1.28 (5 H, m), 1.23 (1 H, m), 1.15 (1 H, m), 1.06-1.01 (2 H, m), 0.88 $\left(3 \mathrm{H}, \mathrm{s}, \mathrm{CH}_{3}\right), 0.87\left(3 \mathrm{H}, \mathrm{s}, \mathrm{CH}_{3}\right), 0.75(1 \mathrm{H}, \mathrm{m}) ; \delta_{\mathrm{C}}(150 \mathrm{MHz}$, $\left.\mathrm{CD}_{3} \mathrm{OD}\right) 224.0$ (C17), 176.7 (C25), 101.8 (C20), 78.5 (C3), 77.8 (C22), 75.4 (C24), 74.9 (C21), 73.7 (C23), 55.8, 52.6, 45.9, 38.1, 36.8, 36.6, 36.3, 35.1, 32.7, 32.0, 30.2, 29.7, 22.6, 21.5, $14.1\left(\mathrm{CH}_{3}\right), 12.6\left(\mathrm{CH}_{3}\right)$, one carbon overlapping or obscured; LRMS (-ESI) $m / z: 465\left([\mathrm{M}-\mathrm{H}]^{-}\right)$; HRMS (-ESI) $\mathrm{m} / \mathrm{z}$ : Calcd for $\mathrm{C}_{25} \mathrm{H}_{37} \mathrm{O}_{8}\left([\mathrm{M}-\mathrm{H}]^{-}\right)$465.2488, found 465.2488.

\section{Abbreviations}

Androstanolone

Androsterone

Boldenone

Coprostanol

Dehydroepiandrosterone

Epiandrosterone

Epitestosterone

Estradiol

Estrone

Etiocholanolone

$\mathrm{d}_{5}$-Etiocholanolone

Mesterolone

Methandriol

Methyltestosterone

Nandrolone
17 $\beta$-Hydroxy- $5 \alpha$-androstan-3-one $3 \alpha$-Hydroxy- $5 \alpha$-androstan-17-one $17 \beta$-Hydroxyandrost-1,4-dien-3-one $5 \beta$-Cholestan-3 $\beta$-ol

$3 \beta$-Hydroxyandrost-5-en-17-one $3 \beta$-Hydroxy- $5 \alpha$-androstan-17-one $17 \alpha$-Hydroxyandrost-4-en-3-one Estra-1,3,5(10)-triene-3,17 $\beta$-diol 3-Hydroxyestra-1,3,5(10)-trien17-one $3 \alpha$-Hydroxy-5 $\beta$-androstan-17-one $2,2,3,4,4-\mathrm{d}_{5}-3 \alpha$-Hydroxy- $5 \beta$-androstan-17-one

$17 \beta$-Hydroxy- $1 \alpha$-methyl-5 $\alpha$-androstan-3-one

$17 \alpha$-Methylandrost-5-ene$3 \beta, 17 \beta$-diol $17 \beta$-Hydroxy-17 $\alpha$-methylandrost4-en-3-one $17 \beta$-Hydroxyestr-4-en-3-one
Pregnenolone

SPE

Testosterone

Trenazone

UGT
$3 \beta$-Hydroxypregn-5-en-20-one

Solid-phase extraction

$17 \beta$-Hydroxyandrost-4-en-3-one $17 \beta$-Hydroxyestra-4,9-dien-3-one Uridine 5 '-diphosphoglucuronosyltransferase

\section{Acknowledgements}

We thank the Australian Research Council (DP110101235) for financial support. We thank Ms Tracy Murray for assistance with protein expression and purification and $\mathrm{Mr}$ Chris Blake for assistance with NMR spectroscopy.

\section{Notes and references}

1 A. V. Stachulski and X. Meng, Nat. Prod. Rep., 2013, 30, 806-848.

2 M. Shipkova and E. Wieland, Clin. Chim. Acta, 2005, 358, 2-23.

3 T. Kuuranne, Doping in Sports: Biochemical Principles, Effects and Analysis, in Handbook of Experimental Pharmacology, ed. D. Thieme and P. Hemmersbach, Springer, Berlin, 2010, vol. 195, pp. 65-75.

4 L. D. Bowers, Annu. Rev. Anal. Chem., 2009, 2, 485-507.

5 M. D. Celiz, J. Tso and D. S. Aga, Environ. Toxicol. Chem., 2009, 28, 2473-2484.

6 P. J. Burke, P. D. Senter, D. W. Meyer, J. B. Miyamoto, M. Anderson, B. E. Toki, G. Manikumar, M. C. Wani, D. J. Kroll and S. C. Jeffrey, Bioconjugate Chem., 2009, 20, 1242-1250.

7 S. C. Jeffrey, J. De Brabander, J. Miyamoto and P. D. Senter, ACS Med. Chem. Lett., 2010, 1, 277-280.

8 K.-C. Chen, S.-Y. Wu, Y.-L. Leu, Z. M. Prijovich, B.-M. Chen, H.-E. Wang, T.-L. Cheng and S. R. Roffler, Bioconjugate Chem., 2011, 22, 938-948.

9 T. Legigan, J. Clarhaut, B. Renoux, I. Tranoy-Opalinski, A. Monvoisin, C. Jayle, J. Alsarraf, M. Thomas and S. Papot, Eur. J. Med. Chem., 2013, 67, 75-80.

10 W. Koenigs and E. Knorr, Ber. Dtsch. Chem. Ges., 1901, 34, 957-981.

11 A. V. Stachulski and G. V. Jenkins, Nat. Prod. Rep., 1998, 15, 173-186.

12 J. Fan, S. M. Brown, Z. Tu and E. D. Kharasch, Bioconjugate Chem., 2011, 22, 752-758.

13 L. Hintikka, T. Kuuranne, O. Aitio, M. Thevis, W. Schänzer and R. Kostiainen, Steroids, 2008, 73, 257-265.

14 T. Kuuranne, O. Aitio, M. Vahermo, E. Elovaara and R. Kostiainen, Bioconjugate Chem., 2002, 13, 194-199.

15 T. Kuuranne, M. Kurkela, M. Thevis, W. Schänzer, M. Finel and R. Kostiainen, Drug Metab. Dispos., 2003, 31, 11171124.

16 R. H. Tukey and C. P. Strassburg, Annu. Rev. Pharmacol. Toxicol., 2000, 40, 581-616. 
17 S. M. Wilkinson, M. A. Watson, A. C. Willis and M. D. McLeod, J. Org. Chem., 2011, 76, 1992-2000.

18 S. M. Wilkinson, C. W. Liew, J. P. Mackay, H. M. Salleh, S. G. Withers and M. D. McLeod, Org. Lett., 2008, 10, 15851588.

19 B. Rakić and S. G. Withers, Aust. J. Chem., 2009, 62, 510-520.

20 S. J. Williams and S. G. Withers, Aust. J. Chem., 2002, 55, 312.

21 W. Schänzer, Clin. Chem., 1996, 42, 1001-1020.

22 M. Thevis, G. Opfermann, H. Schmickler and W. Schänzer, J. Mass Spectrom., 2001, 36, 159-168.

23 M. Thevis, G. Opfermann, H. Schmickler and W. Schänzer, J. Mass Spectrom., 2001, 36, 998-1012.

24 M. Tsivou, N. Kioukia-Fougia, E. Lyris, Y. Aggelis, A. Fragkaki, X. Kiousi, P. Simitsek, H. Dimopoulou, I.-P. Leontiou, M. Stamou, M.-H. Spyridaki and C. Georgakopoulos, Anal. Chim. Acta, 2006, 555, 1-13.
25 R. L. Gomes, W. Meredith, C. E. Snape and M. A. Sephton, J. Pharm. Biomed. Anal., 2009, 49, 1133-1140.

26 A. Fabregat, O. J. Pozo, J. Marcos, J. Segura and R. Ventura, Anal. Chem., 2013, 85, 5005-5014.

27 K. Amarasinghe, P.-S. Chu, E. Evans, R. Reimschuessel, N. Hasbrouck and H. Jayasuriya, J. Agric. Food Chem., 2012, 60, 5084-5088.

28 J. P. Scarth, A. D. Clarke, P. Teale and C. M. Pearce, Steroids, 2010, 75, 643-652.

29 World Anti-Doping Agency (WADA) Funded Research Projects 2011: http:/www.wada-ama.org/en/Science-Medicine/ Research/Funded-Research-Projects/ (accessed February 17, 2014).

30 S. Park and I. Shin, Org. Lett., 2007, 9, 619-622.

31 M. Chen, D. Howe, B. Leduc, S. Kerr and D. A. Williams, Xenobiotica, 2007, 37, 954-971.

32 J. F. Becker, Biochim. Biophys. Acta, 1965, 100, 574-581. 